\title{
Public-Private Partnerships for agricultural innovation: opportunities and challenges in world practice
}

\author{
Oksana Trotsenko, and Sergey Slukin \\ Ural State University of Economics, 620144 Ekaterinburg, Russia
}

\begin{abstract}
The importance of Public Private Partnership (PPP) in agriculture is understood in terms of a shared mechanism among partners for input, resource, market, risk, technology and benefits. In addition, review of various studies indicated the visibility of PPP in various facets of knowledge management, capacity building of youth, development of high end technologies, processing and market promotion in agriculture. The partnership approach apart from developing certain technologies also empowered farmers in terms of enhanced access to technology and market in Russia through organized farmers groups. The limitations of PPP such as focus mainly on high end technologies, high profit margin areas and crops, perceived mistrust and lack of transparency and non-adherence to agreement among partners could be overcome through appropriate working mechanism and policy support. Establishing PPP cell at research and development organizations would spearhead the growth of PPP and thereby sustainable agriculture and livelihood of millions of farm in Russia. The article will be interesting and useful for students of law and economic faculties, it helps them to understand the latest techniques relevant to a particular sector in PPP and or to understand how responses developed in jurisdictions where PPP is firmly established might be applied to new markets.
\end{abstract}

\section{An approach for mutual benefits}

When markets for the delivery of innovation fail, generally at the early stage of research, for the provision of social and environmental services or at the stage of adoption, governments may consider different policy alternatives, such as public investment, policy instruments such as subsidies or tax incentives, and a PPP approach. The decision for the government to adopt a PPP approach to pursue a given objective should be guided by the balance of costs and benefits, compared with other alternatives, as participation in PPPs should be for all innovation actors. The fundamental rationale for public and private actors to join forces in a PPP arises when individual actors alone cannot produce the same service or output, or do it at a higher cost. For both the public and private sectors, the benefits from PPPs come from the pooling of resources and the complementarity of capacities, while risks and costs are reduced because they are shared. Compared to subsidies, PPPs help avoid impeding further development, and allow for the development of integrated solutions. 
Two cost-related issues need, however, to be considered with respect to PPPs: transaction costs and risk of failure. The rationale for the government to engage in PPPs for innovation is to increase economic and social benefits from investments in public research by: improving the leverage of public support to business Research and Development through cost and risk sharing, securing higher-quality contributions by the private sector to government mission-oriented $\mathrm{R} \& \mathrm{D}$ and opening new avenues for commercial spillovers from public research, fostering the commercialisation of results from public research, upgrading knowledge infrastructures [1].

Public research, most often of a basic and fundamental nature, is interested in partnering with the private companies closer to technological development, which will develop the technologies for the industry. For business, partnering with public research can offer solutions to problems, develop new markets or generate value through cooperation and coproduction (OECD, 2014). Improving the transfer of knowledge from public research institutions is often a main motivation for the public sector to engage in PPPs in agricultural innovation systems. Leveraging scarce public research funding is another driver [2]. As private investment typically concentrates in areas where the private returns on investment are high, PPPs can be used to re-orient innovation efforts towards areas with public good aspects, long time horizons and more risks. Innovation actors are increasingly using PPPs to enhance vertical coordination in the value chain. The emphasis in this case is less on the joint creation of new knowledge, than on the efficient dissemination of existing knowledge to firms which can utilise such knowledge for integrating global value chains and competing on world markets. In the agri-food sector, non-public partners range from input suppliers and farmers to processors, retailers, NGOs and consumers' representative. The inclusion of a wide representation in partnerships is expected to facilitate adoption and consumers' acceptance of innovation. The division of labour between the public and the private sectors vary along the Technology Readiness Level (TRL) scale starting from basic research and ending with implementation of operational systems [5]. It depends on the technology readiness, uncertainty, and whether research is generic or dependent on local conditions. Public funding focuses on early stages and research with high genericity and uncertainties. At these stages, knowledge and publications are the main output. The share of private funding and the theoretical scope for partnerships increase along the TRL scale. There are also cases when joining forces is the only alternative. As innovation processes become more complex and social needs evolve, PPPs respond to the partial failure of other policy instruments to achieve objectives. In some areas, PPPs are the only way to obtain social benefits, for example to pursue global challenges that require concerted action and new strategies, such as climate change, biodiversity, ageing farmers, food security, to build very expensive physical and knowledge infrastructure, or to deal with complex problems and strategic challenges such as green growth, requiring multiple skills and sometimes multidisciplinary approaches.

In addition to policy and market failures, the rationale for PPPs in the area of innovation also include coordination failures, although other policy instruments could be used to address them (e.g. tax credits for collaboration). The general rationale for public intervention in innovation such as skills development, network development, or the ability to join in global innovation networks are also cited as reasons for PPPs in this area (OECD, 2014). PPPs help build new innovation capabilities, improve connectivity between national innovation systems and provide compatible incentives to all stakeholders. Fostering links and understandings between public and private researchers, but also between the research and business/farm community, can be particularly useful in:

- lowering transaction costs between players, facilitating thus future cooperation;

- improving knowledge transfer, where a smaller organisation or country lacks capacity to fund the critical mass necessary to enable spill-in of knowledge. 
Longer-term relationships also help improve inter-ministerial or federal/sub-national coordination on innovation issues, and thus policy coherence. Increasingly, PPPs are also considered as a strategic tool to help foster structural change and competitiveness [2].

Current approaches to industrial policy consider PPPs in innovation as a tool to help countries foster structural change. A number of OECD countries are mobilising strategic PPPs to restore or create industrial competitiveness through investment in innovative and industrial projects (OECD, 2014). PPPs for innovation are also considered as a means of orienting public investments into strategic PPPs, and strengthening innovation systems.

\subsection{Evidence from case studies}

Drawing on the lessons from four country case studies - Australia, Austria, France and the Netherlands - OECD (2004) finds PPPs to be a useful tool to promote research cooperation and to build innovative networks in new multidisciplinary research fields. In addition, the study identifies broader benefits of PPPs for innovation, listed in Illustration 1.

Considering PPPs for agricultural innovation in Latin America, Hartwich (2005 and 2007) identify expected private and social benefits from agricultural innovation and from a PPP approach to innovation. Some of them are general, while others are more specific to the developing country context.

Illustration 1. Broad benefits from Public-Private Partnerships for innovation

- Input and output additionality. Cost sharing arrangements and industry leadership within PPPs translate into high leverage of public support on business R\&D and innovation.

- Behavioural additionality. PPPs have a long lasting impact on the behaviour of public and private researchers, contributing to building trust and personal networks which facilitate further formal and informal cooperation.

- Improved R\&D procurement. PPPs can be a more effective way than R\&D contracts to mobilise private financial resources and competencies in pursuing government missions (e.g. in areas such as health and environment) when the contribution of public research organisations are key to success.

- New avenues for commercial spill-over from public research. PPPs provide participating firms with easier access to public research outputs, and facilitate the creation of new technology-based firms, especially spin-offs from public research, as well as the mobility of human resources between the public and private sectors.

- Linking Small and Medium Enterprises (SME) with scientific research. PPPs can play the role of effective bridging institutions to establish contacts between SMEs and universities or research agencies.

- Improved inter-ministerial coordination on innovation issues. PPPs can provide opportunities and incentives for improved inter-ministerial coordination but their design and operation may suffer from inter-ministerial competition.

- Increased synergies between regional innovation systems. National PPP programmes can enhance the cooperation between different local innovative clusters in order to ensure critical mass and better exploit complementarities.

The FAO review of PPP projects for sustainable agricultural development in 15 countries identifies the respective roles of public and private actors and the main benefits they derived from partnerships [3]. Overall, more than half of PPPs were for value-chain development and close to a quarter for innovation and technology transfer. Public partners were primarily responsible for defining the public benefits to be achieved through the adoption of PPP projects and identifying priorities in line with national socio-economic development plans. They also created the enabling environment for agri-PPPs through the provision of supporting rural infrastructure, financial incentives for firms to participate and regulations to protect important aspects such as land rights and intellectual property. Private 
partners generally led the implementation of projects on the ground by securing financing and markets for value-added agriculture and innovation products. The role of the NGOs revolved around ensuring inclusion of smallholders and SMEs, organising producers into groups to reduce transactions costs, and providing technical support. Producers acted as both beneficiaries of PPP projects (i.e. adopters of innovations) as well as private partners through their role as suppliers of raw materials. Benefits from partnering for the public sector included the potential to leverage investment, access new technology and improve management skills (soft skills). For the private sector, firms were able to enter into new markets with lower risk, access local genetic material and trial new technology with greater protection of intellectual property rights.

\section{Governance and implementation challenges}

The potential benefits of PPPs for innovation in food and agriculture explain why they are increasingly used at local, national and global levels. They pose, however, specific challenges in terms of policy choice, governance and implementation. The main challenge with PPPs is to identify when they are a better policy approach for the government, and clearly define the respective roles of the public and private sectors to avoid distorting markets. Conversely, the government needs to identify when they are not possible or desirable. There are also other types of limitations: For example, when considering PPPs for research and innovation, the difficulties related to pursuing common interests through networks including private firms has been noted in the literature. Meeting different interests (farmers want solutions to increase their income, researchers new topics for work, and private companies a technology generating sales) may lead to the exclusion of more performant options, in particular from an environmental point of view.

According to the World Bank, while collaboration is expected to help attain efficiency gains, mobilise resources and investments, develop innovative solutions and reduce risk, PPPs present a number of challenges for policy-makers:

- They blur the boundary between public and private roles, and run the risk of distorting markets if the respective roles of public and private partners are not clarified and public funding subsidises private benefits.

- They require appropriate public institutions and legislative arrangements, and do not compensate for lack of government capacity.

- To ensure sustainability, the interest of private partners to generate revenue should be factored in.

- They may undermine the capacity of public research to pursue basic research needed for longterm public interest.

While partnership diversity in terms of economic size, regional scale, objectives, field of expertise and culture can be enlightening, it also creates additional coordination challenges. Strong governance mechanisms are needed to ensure transaction costs and risks of failure are kept at minimum [7].

\subsection{Evidence from case studies}

The transaction costs of entering into partnerships involve the costs of negotiating the partnership; funding, governance, and legal aspects of the partnerships; and the redistribution of benefits. Costs also arise from communication during the partnership, meetings to report on progress and discuss additional actions, monitoring of activities, evaluation of intermediate results, and administration of the partnerships. Implementation challenges also come from differences in objectives, skills and culture between partners, and from lack of clarity on objectives, resources, and the sharing of costs, risks and benefits 
[8]. For longer-term objectives such as sustainability in particular, it is important for the government to understand the motivation of other partners to provide balanced and critical guidance needed to maintain the cap, and to make sure vested interests do not redirect public funds for their own benefit at the expense of other partners in the group. Institutional arrangements (and external audits) can help guard against capture by special interests.

Public-Private Partnerships for development

- Bureaucratic procedure on the part of the public sector.

- Different working styles and reward structures.

- Lack of business culture in the public sector and limited experience of working in commercial settings.

- No tradition or experience of working with the private sector or even in partnership more generally

- Lack of trust.

- Complex Intellectual Property Right (IPR) issues, especially where multiple public and private partners are involved operating in a number of countries.

- Weak negotiating and IPR skills in the public sector.

- Private sector concerns that unpredictable policy changes may affect partnership agreements.

- Fragmentation of public scientific resources across different ministries and weak communication channels even within the public sector.

- PPP that involve Northern partner collaborating with public research partners in the South often do not lead to useful.

Public-Private Partnerships (PPPs) are increasingly used in agricultural innovation to leverage public funds, enhance efficiency, and improve the adaptation of innovation to demand so as to foster wider and faster diffusion. For governments, PPPs for innovation are but one policy option, whose costs and benefits need to be compared with those of other options. Governments have put in place a policy and regulatory environment to facilitate the development of PPPs for innovation, including financing mechanisms and Intellectual Property (IP) protection. Most programmes are not specific to the food and agriculture system, but apply to the economy-wide innovation system. The main a priori conditions for forming a successful partnership between public and private participants are existence of common objectives, sharing of mutual benefits, and complementarity of human and financial resources. Institutional arrangements need to be clear, but the degree of formality can vary [6]. Elements of good governance include setting clear objectives and rules, and implementing regular monitoring and evaluation that use well-established, open and competitive processes to select PPPs for public participation. Transparency is desirable at all stages of implementation. Improving partners' capacity to design, manage and participate in PPPs is an important factor of success, and is particularly relevant for agricultural innovation.

\section{References}

1. Business and Industry Advisory Committee to the OECD (BIAC) Issues Paper, 10 October 2014. http://www.oecd.org/site/agrfen/meetings/6th-oecd-food-chain-analysisnetwork-meeting-october2014.htm

2. UNECE, Guidebook on promoting Good Governance in Public-Private Partnerships, cited in STDF (2012). www.standardsfacility.org/sites/default/files/STDF_PublicPrivatePartnerships_EN_0.p df 
3. Plan d'action 2016, Agence nationale de la recherche, July. www.agencenationalerecherche.fr/financer-votre-projet/plan-d-action-2016

4. Clarifying the role of partnerships between public and private sectors in international development, BIAC Discussion Paper. http://biac.org/wp-content/uploads/2014/10/1409-10-FINBIAC-Paper-on-PPPs-in-International-Development2.pdf

5. C. Bitaud, Public-Private Partnerships in the agricultural, Knowledge and Innovation System: French initiatives, presentation to the 6th meeting of the OECD Food Chain Analysis Network on PPPs for agricultural innovation, 13-14 October 2014, Paris, (2014)

6. K. Koschatzky, H. Kroll, M. Meyborg, T. Stahlecker, A. Dwertmann, M. Huber, Public-private partnerships in Research and Innovation - Case studies for Australia, Austria, Sweden and the United States, Working Papers Firm and Region No. R2/2015, Fraunhofer Institute for Systems and Innovation Research (2015)

7. K. van der Meer, Public-Private Cooperation in Agricultural Research: Examples from the Netherlands, Agricultural Research Policy in an Era of Privatization (Wallingford: UK: CABI Publishing, 2002)

8. K.O. Fuglie, A.A. Toole, American Journal of Agricultural Economics, 96 (3), 862 (2014) http://dx.doi.org/10.1093/ajae/aat107 